\title{
Effect of Objective Structured Clinical Examinations (OSCE) and Direct Observation Assessment Methods on Nursing Students' General Conditions and their Clinical Achievements " A Comparative Study"
}

\author{
Magda A. Mohamed \& Awatef El-Sayed Ahmed El-Sayed. \\ Associate prof Adult Nursing Department, Faculty of Nursing, Taif, University, Assiut University Egypt. \\ prof. Pediatric nursing department, Faculty of Nursing, Dammam university, Assiut University Egypt.
}

\begin{abstract}
Aim of the present study was to compare the effect of Objective Structured Clinical Examinations (OSCE) and direct observation methods of assessment among nursing Students. Subject and methods :Twenty four nursing students,2nd year-Apply medical Science-Taif university, KSA were included in the study. Two tools were used to collect data for the present study, first is, a structured self-administered questionnaire to collect data related psychological, cognitive, physiological and general effects of exams on students. Second, an observational Checklist was developed for each procedure to assess students' clinical performance. Pass is considered when at least $60 \%$ of marks obtained in both exam with direct observation and OSCE methods. Results of the present study revealed that statistically significant differences were found between clinical exams using the direct observation and OSCE methods related to physiological and general effects. No statistically significant differences were found between clinical exams using the direct observation and OSCE methods related to psychological and cognitive effects as well as students' clinical achievements. The present study concluded that general effect of exam on students were better when using OSCE than the direct observation assessment method. The present study recommended that OSCE should be used as a method of assessment the clinical achievement for nursing students and further studies should be done in this area.
\end{abstract}

\section{Keywords: OSCE, Direct observation method of assessment, Traditional \&Evaluation}

\section{Introduction}

Assessment is a vital part of nursing curricula as it drives the learning process so it must adequately test the goals or objectives set by teachers (Mazin, 2010). Evaluation is the systematic and continuous process of determining the extent to which the student achieves educational objectives. It includes selecting appropriate methods and techniques and administration and interpretation of results. The selection of suitable assessment or evaluation depends on its validity, reliability and practicability, feasibility and acceptability to clinical instructors and students (Basavanthappa, 2004). The purpose of evaluation is to improve the learning and instruction, it helps the learners to know what they should learn, provide information about their progress and recognize the areas of learning difficulties (Aleyamma , 2002 ).

Clinical evaluation is a critical element in professional education program. In nursing it is very important to assess the student's competency in actual practice. The main purpose of clinical evaluation is to assess the quality and standard of students' clinical performance and to give them feedback to facilitate achievement of objectives (Basavanthappa , 2004).
Noohi et al., (2008), and Case et al., (2009), noted that evaluation methods in most clinical courses, besides not matching the educational goals are not effective enough in assessing clinical skills and performances of students and although clinical skills and practice play the main roles in training different groups of nursing, the success of trainees of these fields depends on what they memorize to some extent,

Since 1970s, Objective Structured Clinical Examination (OSCE) has become more accepted as a performance-assessment tool and is now used in many nursing schools. OSCEs can assess students' clinical competencies in a comprehensive, consistent and standardized manner. It is a proven valid and reliable, formative and summative tool for assessing the clinical skills learned by students of health sciences. Multiple studies have shown the impact of OSCE on learning of performance skills. OSCEs help students to develop procedural, communication and physical examination skills (Mondal et al., 2012). Many authors supported OSCE and stated that, during the past 40 years gradual evolution in different methods of clinical evaluation and the appearance of structured objective clinical evaluation as a method of assessing clinical competency in nursing education 
is one of them. At present, this method has attracted considerable attention because of high level of reliability, credit and objectivity, content validity of the achieved skills, fairness, creating motivation for learners, and instructors' and students' satisfaction (Chehrzad et al., 2004, Rushforth, 2007, Walsh et.al., 2009, Furlong et al., 2005 \& Selim et al., 2012).

A complete evaluation program me requires total faculty planning and participation. The objective structured clinical examination (OSCE) method of evaluation is more comprehensive, systematic and objective and provides a uniform basis for evaluation of students OSCE assess the students' performance regarding specific clinical skill. It involves rotation of the individual student through a number of practical and theoretical stations where the students will be assessed using a set of criteria in each station (Belay et al 2008, Bhat et al., 2006 \& Nicholas et al., 2003).

Different studies have confirmed that OSCE is a fair and objective method in assessing clinical skills (Stewart et al., 2011 \& Huang et al., 2007). According to this fact that the course of nursing skills and principles is one of the basic courses in clinical education of nursing students and learning techniques before starting clinical training are of prime importance and students' satisfaction rate with the evaluation method can be effective in creating motivation in their learning.

Direct observation method of assessment is the most valid way to assess students' skills, it can be used for both formative and summative assessments. in formative assessment, tutors, and clinical staff can observe students and give feedback on their performance while for summative assessment teachers or external examiners can observe students' competency in skills. It is important to use a standardized checklist to reduce variations in scoring among different observers and increase the reliability of the assessment (WHO,2003).

The traditional method of practical examination is considered direct observation method of assessment, used when a student is assigned a patient to identify his needs and or problems, formulate nursing diagnosis, set objectives and goals, plan the nursing intervention and implement the planned nursing activities as well as evaluate the outcome (Belay et al., 2008 ,Bhat et.al. 2006 and Nicholas et al., 2003) .

Questioning students during observation can assess their ability to integrate knowledge, skills and attitudes. Oral questioning are best used during direct observation rather than as an isolated assessment method (WHO,2003).
Our Department of nursing usually use the traditional methods of practical exam (direct observation method of assessment) and starts to apply OSCE since (2012), as part of clinical assessment of undergraduate students and this is the first attempt to look at student's perception for the acceptability and preference and in addition to understand student's feeling toward standardized patients

Evaluation of OSCE experience by students helps to solve the question of its application as new mode of assessment and also defines some of deficiencies and obstacles in the preparation and conduction of this examination.

\section{Aim of the study}

The aim of the present study was to compare the effect of objective structured clinical examinations (OSCEs) and the direct observation assessment methods on the $2^{\text {nd }}$ year nursing students general conditions and academic achievements at Taif University.

\section{Materials \& Method}

\section{Operational definition}

General conditions of students means physical, cognitive and psychological state of the student.

Direct observation method means the traditional assessment methods .

\section{Research questions}

The study answered the following questions

- Does summative clinical assessment using the objective structured clinical exam has impact on the student's physical, psychological and cognitive state?

- Does summative clinical assessment using the direct observation method has impact on the student's physical, psychological and cognitive state?

- Are there differences in students' academic clinical achievements when using the two methods of clinical assessment?

\section{Research design}

Descriptive, comparative research design was used to compare the effect of objective structured clinical examinations (OSCE) and the traditional assessment methods (direct observation method) on the $2^{\text {nd }}$ year nursing students' general conditions and academic achievements at Taif University in a selected nursing courses and to describe their attitude toward this new adopted assessment method. 


\section{Setting of the study}

The study was conducted in Nursing DepartmentCollege of Applied Medical Sciences -Taif University. It includes four departments (nursing, physiotherapy, radiology \&lab. Departments) with total number of staff 59, those who are related to nursing department are 21 staff and 42 total students.

\section{Subjects of the study}

All students registered in Nursing Department, College of Applied Medical Sciences -Taif University during the academic year 2013, studying Fundamentals of Nursing Courses, had no experience in OSCE were included in the study sample, their number was 24 students.

\section{Tools of data collection}

Two tools were used to collect data for the present study:

- A structured self-administered questionnaire was adopted and modified form previous researches (Bagheri et al., 2012) \& administered to collect data related effects of exams on students included: 22 questions which divided as:

- Four questions concerning the psychological effects

- Seven questions concerning the cognitive effects

- Four questions concerning the physiological effects, \&

- Seven questions concerning the general effects, each student asked to respond to all of the items, honestly\& answers using a 5-points Likert type agreement scale anchored with a 1 (Strongly Disagree) and a 5 (Strongly Agree). The Cronbach Alpha coefficient of the instrument was 0.85 for the study sample. The instrument had high construct validity (with a part-whole correlation of 0.91) (Kerlinger, 1986-2010).

- B- Observational Checklists were developed for five procedures, that used in OSCE and in the direct observation methods of assessment to assess the students' summative clinical performances.

\section{Methods of data collection}

\section{Ethical consideration}

- Permission to conduct the study was obtained from the Research Committee in College of Applied Medical Sciences - Taif University

- An informed consent was obtained from all the participants before collecting data. Explanation of the study aim in a simple and clear manner was done to each participant. No harmful maneuvers and no hazards were anticipated. All data were considered confidential. Participants were informed about their right to withdraw from the study at any time without giving any reason.
- Clinical Performance of all participants was measured two times using the direct observation method of assessment in the first semester for fundamentals of Nursing 1 course, and OSCE in the second semester for Fundamental of Nursing II course. Same examiners were examined students in both methods. Pass is considered when at least $60 \%$ of marks obtained in both exams with the direct observation and OSCE methods of assessment.

- The Direct Observation Method

To assess the summative clinical performance was applied to all students in the first semester for the Fundamentals of Nursing I Course as the following

- Identification of all procedures needed for examination as vital signs, hand washing ,scrubbing,positioning and exercise ,injections (intramuscular IM, subcutaneous SC, and intradermal ID).

- -Each procedure name is recorded in a separate paper

- -Each student asked to pick one of the papers randomly, read it, and start to carry out the procedure in front of the instructor, the instructor observed student and gave her marks according previous performed checklist, the time of performing the procedure is changed according to the student and the complexity of the technique.

- Each students asked to answer 2 written short answer questions related to the procedure to assess her ability to integrate theory and practice. These questions were previously prepared and scored for each procedure (Total score was modified to $\mathbf{5 5}$ marks)

- Objective Structured Clinical Examination (OSCE) was performed to assess all students' summative clinical performance in the second semester for the Fundamentals of Nursing II course as the following

- Before starting of the final exam, the researchers discuss the overall experimental processes and explained what and why OSCE is a useful tool for assessment.

- According to the available facilities, number and types of procedures were determined. 10 stations were specified for OSCE with 5 minutes to each station. All required instructions for students and examiners were written in a format and with explicit marking criteria, Instructions format distributed between students and examiners immediately before OSCE carried out. Knowledge and practices were based on the 
training guide and objectives of Fundamentals of Nursing II course.

- Stations used in OSCE divided as:

- Four stations aimed to test clinical competences of student including: wound dressing, intravenous injection, Bladder catheterization \& nose-gastric tube insertion .Five minutes is specified to each procedure, all the students carried out procedures \& assessed by examiners on the basis of the previously performed checklist.

- Six stations to assess students' cognitive skills including photos for range of motion ,bandages, first aid for chemicals, eye burn \& epistaxis, as well as name of equipment needed for suctioning, bladder catheterization, and blood transfusion procedures. Five mints is specified for each station. All students asked to write their answers in previously structured answer sheets for each station. All sheets are corrected by assigned examiners and marked according student's answers. Each station must assess students skills needed in course, the maximum allotted marks of OSCE was 55 marks.

- Immediately at the end of each type of exam, (Direct Observation Method of assessment that used to assess students' summative clinical exam for Fundamentals of Nursing I course in the first semester\& Objective Structured Clinical Exam OSCE Method of assessment that used to assess students' summative clinical exam for Fundamentals of Nursing II course in the second semester), each student asked to fill the previously developed questionnaire to collect data related effect of exams on students' state. This questionnaire was studied by some nursing researchers and its content validity was confirmed, and its reliability was also confirmed through test-retest method ( $r=0.75)$.distribution the questioner was used to investigate the students' physiological, psychological and cognitive state due to the application of 2 different assessment methods for their summative clinical exam.

- Student's achievement in clinical exam in the first and the second semesters determined as the following: Excellent ranged from $90 \%$ to 100 $\%$, Very good ranged from $80 \%$ to $<90 \%$, Good ranged from $70 \%$ to $<80 \%$ and pass ranged from $60 \%$ to $<70 \%$ of the total exam score.

\section{Statistical Analysis}

Data entry and statistical analysis were done using SPSS ver. 16.0 statistical software packages. Data were presented using descriptive statistics in the form of frequencies and percentages for qualitative variables, mean and standard deviations for the quantitative variables. Pearson t-test was used for assessment of the inter-relationships among quantitative variables. Statistical significance was considered at $\mathrm{p}$-value $<0.05$. 


\section{Results}

Table (1) Number and percentages of students' responses related to psychological effects of the direct observation and OSCE methods of their summative clinical assessment $\mathbf{N}=\mathbf{2 4}$.

\begin{tabular}{|l|c|c|c|c|}
\hline \multirow{2}{*}{ Items of the psychological effects } & \multicolumn{2}{|c|}{$\begin{array}{c}\text { Direct Observation Method } \\
\text { of Assessment N=24 }\end{array}$} & \multicolumn{2}{|c|}{$\begin{array}{c}\text { OSCE Method of Assessment } \\
\text { N=24 }\end{array}$} \\
\cline { 2 - 5 } & Agree & Disagree & Agree & Disagree \\
\cline { 2 - 5 } & $\mathbf{N}(\boldsymbol{\%})$ & $\mathbf{N}(\mathbf{\%})$ & $\mathbf{N}(\boldsymbol{\%})$ & N $(\%)$ \\
\hline Calmness before exam & $0(0)$ & $24(100)$ & $4(16.7)$ & $20(83.3)$ \\
\hline Stress for exam & $16(66.7)$ & $8(33.3)$ & $14(58.3)$ & $10(41.7)$ \\
\hline Stress while performing the techniques & $16(66.7)$ & $8(33.3)$ & $18(75)$ & $6(25)$ \\
\hline Stress from time limitation & $16(66.7)$ & $8(33.3)$ & $18(75)$ & $6(25)$ \\
\hline
\end{tabular}

Table (2): Mean score \pm SD related to psychological effects of the direct observation and OSCE methods of assessment as responded by students $\mathbf{N}=\mathbf{2 4}$.

\begin{tabular}{|c|c|c|c|}
\hline \multirow[b]{2}{*}{ Items } & \multicolumn{2}{|c|}{ Methods of students' assessment } & \multirow[b]{2}{*}{$\mathbf{P}$-value } \\
\hline & $\begin{array}{l}\text { Direct Observation } \\
\text { Method }(n=24)\end{array}$ & $\begin{array}{c}\text { OSCE } \\
\text { Method }(n=24)\end{array}$ & \\
\hline $\begin{array}{l}\text { Psychological effects ( total } 20 \text { grads) } \\
\text { X } \pm \text { SD } \\
\text { Minimum } \\
\text { Maximum }\end{array}$ & $\begin{array}{c}13.6 \pm 1.5 \\
11.00 \\
16.00\end{array}$ & $\begin{array}{c}13.2 \pm 3.0 \\
6.00 \\
16.00\end{array}$ & $\begin{array}{c}\mathrm{t}=0.59 \\
\mathrm{P}=0.55 \\
(\mathrm{NS})\end{array}$ \\
\hline
\end{tabular}

$N S=$ No statistical significant differences

Table (3): Number and percentages of students' responses related to cognitive effects of the direct observation and OSCE methods of their summative clinical assessment $\mathrm{N}=24$.

\begin{tabular}{|c|c|c|c|c|}
\hline \multirow[t]{3}{*}{ Items of the cognitive effects } & \multicolumn{2}{|c|}{$\begin{array}{c}\text { Direct Observation } \\
\text { Method of Assessment N } \\
=24\end{array}$} & \multicolumn{2}{|c|}{$\begin{array}{l}\text { OSCE Method of } \\
\text { Assessment N=24 }\end{array}$} \\
\hline & Agree & Disagree & Agree & Disagree \\
\hline & $\mathbf{N}(\%)$ & $\mathbf{N}(\%)$ & $\mathbf{N}(\%)$ & $\mathbf{N}(\%)$ \\
\hline Confusion while taking the exam & $20(83.3)$ & $4(16.7)$ & $12(50)$ & $12(50)$ \\
\hline $\begin{array}{l}\text { Assess our clinical skills, skills in } \\
\text { communication and approaching patients }\end{array}$ & $14(58.3)$ & $10(41.7)$ & $18(75)$ & $6(25)$ \\
\hline $\begin{array}{l}\text { Assess our abilities in solving clinical } \\
\text { problems }\end{array}$ & $14(58.3)$ & $10(41.7)$ & $4(16.7)$ & $20(83.3)$ \\
\hline Easy performing the techniques & $8(33.3)$ & $16(66.6)$ & $10(41.7)$ & $14(58.3)$ \\
\hline complexity of the method of the exam & $8(33.3)$ & $16(66.6)$ & $14(58.3)$ & $10(41.7)$ \\
\hline $\begin{array}{l}\text { encouraging the students to active } \\
\text { participation in learning }\end{array}$ & $8(33.3)$ & $16(66.6)$ & $14(58.3)$ & $10(41.7)$ \\
\hline Assess our performance in action & $18(75)$ & $6(25)$ & $18(75)$ & $6(25)$ \\
\hline
\end{tabular}

Table (4): Mean score \pm SD related to cognitive effects of the direct observation and OSCE methods of assessment as responded by students' $\mathbf{N}=\mathbf{2 4}$.

\begin{tabular}{|l|c|c|c|}
\hline \multirow{2}{*}{ Items } & \multicolumn{2}{|c|}{ Methods of students' assessment } & \multirow{2}{*}{ P - value } \\
\cline { 2 - 4 } & Direct Observation Method $(\mathbf{n}=\mathbf{2 4})$ & OSCE Method $(\mathbf{n}=\mathbf{2 4})$ & $\mathrm{t}=1.3$ \\
\hline Cognitive effect (35 grads)X \pm SD & $24.5 \pm 3.05$ & $23.7 \pm 2.8$ & $\mathrm{P}=0.307$ \\
Minimum & 18.00 & 19.0 & $\mathrm{NS}$ \\
Maximum & 29.0 & 29.0 & \\
\hline
\end{tabular}

$N S=$ No statistical significant differences 
Table (5): Number and percentages of students' responses related to physiological effects of the direct observation and OSCE methods of their summative clinical assessment $N=24$.

\begin{tabular}{|c|c|c|c|c|}
\hline \multirow{3}{*}{$\begin{array}{c}\text { Items of the physiological } \\
\text { effects }\end{array}$} & \multicolumn{2}{|c|}{$\begin{array}{c}\text { Direct Observation Method of } \\
\text { Assessment } \mathrm{N}=\mathbf{2 4}\end{array}$} & \multicolumn{2}{|c|}{ OSCE Method of Assessment $\mathrm{N}=\mathbf{2 4}$} \\
\hline & Agree & Disagree & Agree & Disagree \\
\hline & $\mathbf{N}(\%)$ & $\mathbf{N}(\%)$ & $\mathbf{N}(\%)$ & $\mathbf{N}(\%)$ \\
\hline Hand tremors & $16(66.6)$ & $8(33.3)$ & $14(58.3)$ & $10(41.7)$ \\
\hline Sleep disturbance & $18(75)$ & $6(25)$ & $14(58.3)$ & $10(41.7)$ \\
\hline Dry mouth & $24(100)$ & $0(0)$ & $0(0)$ & $24(100)$ \\
\hline Rapid respiration \& heart rate & $14(58.3)$ & $10(41.7)$ & $10(41.7)$ & $14(58.3)$ \\
\hline
\end{tabular}

Table (6): Mean score \pm SD related to physiological effects of the direct observation and OSCE methods of assessment as responded by students $\mathrm{N}=\mathbf{2 4}$.

\begin{tabular}{|c|c|c|c|}
\hline \multirow[b]{2}{*}{ Items } & \multicolumn{2}{|c|}{ Methods of students' assessment } & \multirow[b]{2}{*}{ P-value } \\
\hline & $\begin{array}{l}\text { Direct Observation } \\
\text { Method }(n=24)\end{array}$ & $\begin{array}{c}\text { OSCE Method } \\
(n=24)\end{array}$ & \\
\hline $\begin{array}{l}\text { Physiological effect (total } 20 \text { grads) } \\
\mathrm{X} \pm \mathrm{SD} \\
\text { Minimum } \\
\text { Maximum }\end{array}$ & $\begin{array}{c}13.3 \pm 2.5 \\
9.0 \\
17.0\end{array}$ & $\begin{array}{c}11.5 \pm 2.6 \\
6.0 \\
15.0\end{array}$ & $\begin{array}{c}\mathrm{t}=2.44 \\
\mathrm{P}=0.018 *\end{array}$ \\
\hline
\end{tabular}

* Statistically significant differences

Table (7) Number and percentages of students' response related to general effects of the direct observation and OSCE methods of their summative clinical assessment $\mathrm{N}=\mathbf{2 4}$.

\begin{tabular}{|l|c|c|c|c|}
\hline \multirow{2}{*}{ Characteristics of exams } & \multicolumn{2}{|c|}{$\begin{array}{c}\text { Direct Observation Method of } \\
\text { Assessment N =24 }\end{array}$} & \multicolumn{2}{c|}{ OSCE Method of Assessment } \\
& Agree & Disagree & Agree & Disagree \\
\cline { 2 - 5 } & $\mathbf{N}(\%)$ & N (\%) & N (\%) & N (\%) \\
\cline { 2 - 5 } & $10(41.7)$ & $14(58.3)$ & $14(58.3)$ & $10(41.7)$ \\
\hline Increases self confidence & $16(66.6)$ & $8(33.3)$ & $18(75)$ & $6(25)$ \\
\hline Fair to all students & $12(50)$ & $12(50)$ & $12(50)$ & $12(50)$ \\
\hline burden on the student & $8(33.3)$ & $16(66.6)$ & $18(75)$ & $6(25)$ \\
\hline $\begin{array}{l}\text { Accurate measurement of } \\
\text { learning\& skill }\end{array}$ & $6(25 \%)$ & $18(75)$ & $14(58.3)$ & $10(41.7)$ \\
\hline Satisfaction of number of exams & $10(41.7)$ & $14(58.3)$ & $18(75)$ & $6(25)$ \\
\hline Detect students' weaknesses & $0(0)$ & $24(100)$ & $16(66.6)$ & $8(33.3)$ \\
\hline $\begin{array}{l}\text { Different types of tests can be } \\
\text { incorporated into it }\end{array}$ & & & \\
\hline
\end{tabular}

Table (8): Mean score \pm SD related to general effects of the direct observation and OSCE methods of assessment as responded by students $\mathbf{N}=\mathbf{2 4}$.

\begin{tabular}{|c|c|c|c|}
\hline \multirow[b]{2}{*}{ Items } & \multicolumn{2}{|c|}{ Methods of students' assessment } & \multirow[b]{2}{*}{$\mathbf{P}$-value } \\
\hline & $\begin{array}{l}\text { Direct Observation } \\
\text { Method }(n=24)\end{array}$ & $\begin{array}{c}\text { OSCE Method } \\
(n=24)\end{array}$ & \\
\hline $\begin{array}{l}\text { Characteristics of exam (total } 35 \text { grads) } \\
\mathrm{X} \pm \mathrm{SD} \\
\text { Minimum } \\
\text { Maximum }\end{array}$ & $\begin{array}{c}22.08 \pm 2.9 \\
18.0 \\
28.0\end{array}$ & $\begin{array}{c}24.6 \pm 1.8 \\
21.0 \\
28.0\end{array}$ & $\begin{array}{c}\mathrm{t}=3.5 \\
\mathrm{P}=0.001 \\
\mathrm{~S} * *\end{array}$ \\
\hline
\end{tabular}

** Highly statistically significant differences 
Table (9): Number and percentages of students' related to their achievement score in the summative clinical exam using the direct observation and OSCE methods of assessment $\mathrm{N}=24$

\begin{tabular}{|l|c|c|c|c|}
\hline \multirow{2}{*}{\begin{tabular}{c} 
Total Marks (55 Marks) \\
\multirow{2}{*}{ Students' Marks }
\end{tabular}} & \multicolumn{4}{|c|}{ Methods of clinical assessment } \\
\cline { 2 - 5 } & $\begin{array}{c}\text { Fundamentals of Nursing1 } \\
\text { Direct observation method (N=24) }\end{array}$ & $\begin{array}{c}\text { Fundamentals of Nursing II } \\
\text { OSCE method (=24) }\end{array}$ \\
\cline { 2 - 5 } & No & $\mathbf{\%}$ & No & \% \\
\hline Excellent $(49.5-55 \%)$ & 10 & 41.7 & 10 & 41.7 \\
\hline Very Good $(44<49.5)$ & 6 & 25.0 & 6 & 25.0 \\
\hline Good (38.5 $<44)$ & 8 & 33.3 & 6 & 25.0 \\
\hline Pass (33<38.5) & 0 & 0.0 & 2 & 8.3 \\
\hline
\end{tabular}

Table (10): Mean score \pm SD of students' related to their achievement in the summative clinical exam using the direct observation and OSCE methods of assessment $\mathrm{N}=\mathbf{2 4}$.

\begin{tabular}{|c|c|c|c|}
\hline \multirow[b]{2}{*}{$\begin{array}{c}\text { Summative Clinical exam } \\
\text { total marks }(55)\end{array}$} & \multicolumn{2}{|c|}{ Methods of clinical assessment } & \multirow[b]{2}{*}{ p. value } \\
\hline & $\begin{array}{c}\text { Fundamentals of Nursing1 } \\
\text { Direct observation method } \\
\mathrm{N}=24\end{array}$ & $\begin{array}{c}\text { Fundamentals of Nursing } \\
\text { II } \\
\text { OSCE method N=24 }\end{array}$ & \\
\hline $\begin{array}{l}\mathrm{X} \pm \mathrm{SD} \\
\text { Minimum } \\
\text { Maximum }\end{array}$ & $\begin{array}{c}47.0 \pm 4.3 \\
41.0 \\
54.0\end{array}$ & $\begin{array}{c}46.7 \pm 6.0 \\
35.0 \\
54.0\end{array}$ & $\begin{array}{c}\mathrm{t}=0.21 \\
\mathrm{P}=0.82 \\
\text { (NS) }\end{array}$ \\
\hline
\end{tabular}

All participants (24) were females, aged from 20 to 23. years old (mean $\pm \mathrm{SD}, 21.08 \pm 1.05$ ) enrolled in the level $\operatorname{III}\left(2^{\text {nd }}\right.$ years $)$ in college of applied medical science - Nursing department Taif University, Kingdom of Saudi Arabia during the academic year 2013-2014 and had no any experience related methods of nursing clinical assessment.

Table (1): Showed number and percentages of students' responses related to psychological effects of the direct observation and OSCE methods of their summative clinical assessment. Hundred percent and $83.3 \%$ of students responded disagree related item of calmness before exam using the direct observation and OSCE methods of assessment respectively. Two third of students $(66.7 \%)$ responded their agreement related items of stress while performing the techniques and stress from time limitation when using the direct observation compared with $(75 \%)$ of them when using OSCE methods of assessment for their summative clinical assessment.

Table (2): Demonstrated Mean score \pm SD related to psychological effects of the direct observation and OSCE methods of assessment as responded by students. No statistical significant difference was obtained between mean score \pm SD related to psychological effects of the direct observation and OSCE methods of assessment as responded by students. (Mean \pm SD 13.6 \pm 1.5 and $13.2 \pm 3.0$ respectively, $\mathrm{P}=0.55)$.

Table (3): noted number and percentages of students' responses related to cognitive effects of the direct observation and OSCE methods of their summative clinical assessment. Majority of students $83.3 \%$ responded agree related item of confusion while exam using the direct observation compared with $50 \%$ of them responded agree related the same item in using OSCE methods of assessment. Different percentages of students agreed that the clinical exam using the direct observation compared to OSCE methods of assessment are assessing clinical skills, skills in communication and approaching patients, Easy performing the techniques $(58.3 \%$ and $75 \%$, $33.3 \%$ and $41.7 \%$, respectively ). One third $33.3 \%$ compared $58.3 \%$, of them responded that both methods are complex and encouraging the students to active participation in learning, More than half of students $58.3 \%$ agreed that clinical exam using the direct observation method is assessing the student's ability to solve clinical problems compared with $16.7 \%$ of them responded their agreement related the same item for using OSCE method. As well as 75\% of students agreed that clinical exam using both the direct observation and OSCE methods are assessing their performance in action

Table (4): Showed mean score \pm SD related to cognitive effects of the direct observation and OSCE methods of assessment as responded by students. No statistical significant difference was found between mean score \pm SD related to cognitive effects of the direct observation and OSCE methods of assessment as responded by students. (Mean \pm SD $24.5 \pm 3.05$ and $23.7 \pm 2.8$ respectively, $\mathrm{P}=0.307)$.

Table (5): Illustrated number and percentages of students' responses related to physiological effects of 
the direct observation and OSCE methods of their summative clinical assessment. All items of physiological effects were more prevalent in using the direct observation than using OSCE methods of assessment as responded by students. Items related to physiological effects of the direct observation and OSCE methods of assessment that responded agreement by students were dry mouth $(100 \%$ and $0 \%)$, sleep disturbance $(75 \%$ and $58.3 \%)$, Hand tremors $(66.6 \%$ and $58.3 \%)$ and rapid respiration and heart rate $(58.3 \%$ and $41.7 \%)$ respectively.

Table (6): Showed mean score \pm SD related to physiological effects of the direct observation and OSCE methods of assessment as responded by students. Maximum score of the physiological effect was 20 . Statistical significant difference was found between mean score \pm SD related to physiological effects of the direct observation and OSCE methods of assessment as responded by students. (Mean $\pm \mathrm{SD}$ $13.3 \pm 2.5$ and $11.5 \pm 2.6$ respectively, $\mathrm{P}=0.018$ ).

Table (7): noted number and percentages of students' response related to general effects of the direct observation and OSCE methods of their summative clinical assessment.

High percentages of students responded their agreement that clinical exam using OSCE method of assessment increase self-confidence $(58.3 \%)$, fair to all student $(75 \%)$, accurate measure of learning \& skills $(75 \%)$,Satisfaction of number of exams $(58.3 \%)$, Detect their weaknesses $(75 \%) \&$ Different types of test method can be incorporated into it $(66.6 \%)$ compared with the direct observation method of assessment $(41.7 \%, 66.6 \%, 33.3 \%, 25 \%$, $41.7 \%$, and $0 \%$ for items listed respectively).

Table (8): Illustrated mean score \pm SD related to general effects of the direct observation and OSCE methods of assessment as responded by students. Maximum score of items was 35. Statistical significant difference was found between mean score \pm SD related to general effects of the direct observation and OSCE methods of assessment as responded by students. (Mean \pm SD 22.08 \pm 2.9 and $24.6 \pm 1.8$ respectively, $\mathrm{P}=0.001)$.

Table(9): Demonstrated number and percentages of students' related to their achievement score in the summative clinical exam using the direct observation and OSCE methods of assessment, it was found that $41.7 \%$ of students' got excellent in the clinical exam using both the direct observation and OSCE methods of assessment . One quarter of students $25 \%$ got very good in the clinical exam using either the direct observation or OSCE methods of assessment, $33.3 \%$ of students got good in the clinical exam using the direct observation compared with $25 \%$ of them got good in the clinical exam using OSCE method methods of assessment. Only $8.3 \%$ of students got pass in the clinical exam using OSCE method.

Table (10): showed Mean score \pm SD of students' related to their achievement in the summative clinical exam using the direct observation and OSCE methods of assessment. No statistically significant difference was found between mean score of students related to their achievement in the summative clinical exam using the direct observation and OSCE methods of assessment. Maximum score of the clinical assessment was 55 marks. Mean \pm SD (47.0 \pm 4.3 and $46.7 \pm 6.0)$ for clinical exam using the direct observation and OSCE methods of assessment

\section{Discussion}

The acquisition of clinical skills is paramount to the development of a safe and competent practitioner (Brookes, 2007). OSCE as a performance-based assessment is a well-established student's assessment tool for many reasons: competency- based, valid, practical and wise effective mean of assessing clinical skills that are fundamental to the practice of nursing and other health care related professions (Alinier, 2003).

Based on results sited above, the present study revealed that both the direct observation and OSCE methods of assessment used in the summative clinical exam of nursing students had psychological, cognitive and physiological effects as responded by them. As for the psychological effect, no statistical significant difference was found between students' responses related to the psychological effects of the direct observation and OSCE methods of assessment in their summative clinical exam, two third of students showed their agreement related items of stress while performing the techniques and stress from time limitation when using the direct observation compared with $(75 \%)$ of them when using OSCE methods of assessment in their clinical exams with shown in tables (1\&2). This may because it is the first time students in the present study are exposing to OSCE experiences with different stations with time limitation. Students considered time limitation is one of the important factor producing stress in OSCE method. These results are congruent with those obtained by Bagheri et al.,( 2012), who mentioned that, students were more stressed during OSCE than in other methods of clinical assessment . It seems that unfamiliarity of students with OSCE.

Regarding the cognitive effect of the direct observation and OSCE methods of assessment in the summative clinical exam as responded by students, the present study pointed that no statistical significant difference was found between mean score \pm SD related to cognitive effects of the direct observation 
and OSCE methods of assessment as responded by students. High percentages of students agreed that clinical exam using OSCE method assessing their clinical skills ,skills in communication\& approaching patients, complexity of the method of the exam \& encouraging the students to be active participation in learning as shown in tables (3\&4). This result confirms credit and high accuracy of OSCE in assessing clinical skills of students which is confirmed by the current study as well. In Mitchell et al.,(2009), has been mentioned that in contrast with various positive specifications of OSCE, for better usage of this method in assessing clinical skills of nursing students, it is essential that this method is used besides other methods of assessment so that more accurate and favorable results will be found for judgment.

In the present study most of the students expressed that OSCE, although being complex, it is an appropriate method of assessing clinical skills, this finding is similarly with Mazin,(2012), who reported that, majority of students felt that OSCE is more difficult than the traditional clinical examination and this can be attributed to influence of anxiety and lack of confidence associated with new assessment . Case et al., (2009), has been mentioned that OSCE is a valid and reliable method for examining clinical skills of nursing students and is more accurate than other methods which matches the results of the present study Mani, et al.,(2012), Anderson \& Stickley, (2002), reported that using OSCE can improve interpersonal relationships of nursing students and communication skills..

The present study revealed that a statistical significant difference was found between mean score \pm SD related to physiological effects of the direct observation and OSCE methods of assessment as responded by students. High percentages of students agreed that hand tremors, sleep disturbance ,dry mouth, rapid respiratory and rapid heart rates are more appeared in the clinical exam using the direct observation compared with OSCE methods of assessment as shown in tables (5\&6). The result is due to the traditional exam does not give students the opportunity to select more than two or three procedure and selected this procedure by luck, in addition to students under stress and anxiety of the exam. The physiologic response to a stressor, whether it is a physical stressor or a psychological stressor, is a protective and adaptive mechanism to maintain the homeostatic balance of the body. The stress response is a "cascade of neural and hormonal events that have short- and long-lasting consequences for both brain and body (Smeltezer et al., 2012).

In addition, the present study demonstrated that a statistical significant difference was found between mean score \pm SD related to characteristics of the direct observation and OSCE methods of assessment as responded by students. high percentages of students responded their agreement that summative clinical exam using OSCE method of assessment increases their self-confidence , fair to all students, , accurate measure of learning \& skills, satisfaction of number of exam, detect their weaknesses and different types of tests can be incorporated into it compared with clinical exam using the direct observation method of assessment as shown in tables (7\&8). Rational of this result all students under exam at the same time and the same procedure and the same clinical instructor. Also OSCE method can be used as a very valuable method for assessing clinical competency of students because of appropriate reliability in comparison to methods such as worksheet, clinical observance, and etc.. These results are supported by Brosnan et al.,'s study (2006), who showed that the students who got higher scores in OSCE assessment method had more selfconfidence for doing clinical practice. Also they mentioned that it was the meaningful and fairer method among methods of assessing clinical skills. Also these findings are in agreement with those obtained by Mazin, (2012), who reported that, majority of students reflected that OSCE is either easier or just similar the direct observation method of assessment. El Nemer \& Kandeel, (2009), in their study reported that most students viewed OSCE as a fair assessment tool which covered a broad area of knowledge, allowed them to compensate in some areas and minimized their chances of failing. Moreover, Nolti et al., (2011), study, students 'opinions regarded OSCE assessment, the result showed that, the greatest parts included, suitable environment to performing a technique, and express his knowledge. The worst parts included: stress and anxiety of student before the exam.

Smith et. al. (2012), compared different methods of assessing midwifery students' clinical skills, the outcome expressed that none of the assessment methods of clinical skills can provide complete information about the students' skills but OSCE method can be used as a very valuable method for assessing clinical competency of medical science students Bagheri et al., (2012)\& Huang et al.,

(2007), Studied medical students' satisfaction with OSCE method. The result of the survey showed that the majority of students were satisfied with the content, atmosphere, performance method, and environment and expressed that its effect on improving clinical skills was pleasing.

As for the achievements of students in their summative clinical exams using the direct observation and OSCE methods of assessment, the 
present study noted that no statistical significant difference was found between students' achievement score in their summative clinical exam using the direct observation and OSCE methods of assessment with higher mean score obtained with using the direct observation method than OSCE method as shown in table $(\mathbf{9 \& 1 0})$. This result due to no previous experience regarding OSCE and Time limitation for section may be no enough for answer question and performed procedure which causes a lot of stress among students. Finding of the present study is not agree with those obtained by Eldarir \& Abd- El Hamid (2013), who reported that, the comparison between ,OSCE versus traditional method of evaluation revealed higher mean OSCE scores with a high statistical significant difference in first trail. This results may be OSCE is a new experience for students in the present study and they were not acquainted with it.

Moreover, findings of the present study revealed that almost students got the same grads in their clinical achievement using either the direct observation or OSCE methods in their clinical exam

\section{Limitation of study}

Although all female students in $2^{\text {nd }}$ year were included in this study, the sample was small as it was difficult to include male's students, according to Kingdom of Saudi Arabia culture.

\section{Conclusion}

The present study concluded that generally clinical exam using OSCE had better effect on students than that using the direct observation assessment method as responded by them, while clinical exam using the direct observation assessment method had better psychological, cognitive, physiological effects on students than that using OSCE. Clinical achievement of students using the traditional method of assessment had slightly better mean score than that using OSCE. Clinical exam using OSCE is more complex and stressful than that using the traditional method. Time limitation is another negative specification of OSCE which causes a lot of stress among students.

\section{Recommendations}

Based on findings of the current study, it is recommended that:

OSCE should be evaluated as a new method of assessment of nursing students' clinical achievement after further studies will be done in this area with larger number of nursing student

\section{Reference}

1. Alinier, G., (2003): lecturers 'perspectives of objective structured clinical examination incorporating simulation. Nurse Education Today., 23(6): 419-426.

2. Anderson, M., Stickley, T., (2002): Finding reality: the use of objective structured clinical examination (OSCE) in the assessment of mental health nursing student's interpersonal skills. Nurse Education in Practice; 2: 160-168

3. Aleyamma K., (2002): Principles of Curriculum Development and Evaluation. first edition. Tamilnadu: Vivekanandha press publisher,

4. Bagheri, M., Forotgheh, M., \& Fallah, S., (2012): The Comparison of Stressors in the Assessment of Basic Clinical Skills with Traditional Method and OSCE in nursing Students, Life Sci J;9(4):1748- 1752] (ISSN:1097-8135).

http://www.lifesciencesite.com. 266

5. Basavanthappa, B., (2004): Nursing education, first edition. New Delhi: J P brother's medical publishers.

6. Belay, S., Tsinuel G., (2008): Objective Structured clinical examination (OSCE): examinee's perception at department of pediatrics and child health,Jimma University. Ethiop J Health Sci. 18(2):47-52.

7. Bhat, S., \& Mary, A., (2006): Objective Structured Clinical Examination (OSCE) Nursing Journal of India. Jan.

8. Brosnan, M., Evans W., Brosnan E., Brown G., (2006): Implementing objective structured clinical skills evaluation (OSCE) in nurse registration programmes in a center in Ireland: An utilization focused evaluation. Nurse Education Today; 26(2): 115-22

9. Brookes, D., (2007): Objective Structured Clinical Examination assessment. www.nursingtimes.net

10. Case, p., M,goeofert, A., Espey E., Keez, M., katz, N., (2009): To the point reviews in education the objective structured clinical examination ,American journal obstetric gynecology200(1):25-34.

11. Chehrzad, M., Shafie, p., Mirzaei, M., Kazem N., (2004): Comparison between two methods: Objective structured clinical evaluation (OSCE) and traditional on nursing students' satisfaction. Journal of Medical Faculty Guilan University of Medical Sciences. Summer13(50):8-13

12. El-Nemer, A., \& Kandeel, N., (2009): Using OSCE as an Assessment Tool for Clinical Skills: Nursing Students' Feedback. AJBAS JulySeptember, 2465-2472. 
13. Furlong, E., Fox, P., Lavin, M., \& Collins, R., (2005): Oncology nursing students ${ }^{6}$ views of a modified OSCE. European Journal of Oncology Nursing (9), 351-359

14. Huang, Y., Liu, M., Huang, C., Liu, K., (2007): Implementation of an OSCE at Kaohsiung Medical University. Kaohsiung J Med Sci. Apr; 23(4):161-9

15. Kerlinger, F., (1986-2010): Foundations of Behavioral Research, 3rd edn. New York: Holt, Rinehart, and Winston, , 102-448-445.

16. Mani M., Zahra M., Tourzani1, Touran B., Babaheydari, Seyedeh Z., Mirfeizi, Mohammad A., Mahyar M., Golbarg k., Mandana G., (2012): Comparative Study on Evaluating of Knowledge and clinical Practices of Midwifery Students in the Courses of Physiopathology, Infectious and Internal Diseases and Surgery based on Objective Structured Clinical Examination and Traditional Assessment Method, FUTURE of MEDICAL EDUCATION JOURNAL, mums.ac.ir/jfmejdecember 21 ,

17. Mazin A., (2010): OSCE, things to be said. Editorial. Bas.J.Surg.; 16:5-6.

18. Mazin A., (2012): Student's perception of OSCE in surgery at Basrah College of Medicine, Bas J Surge, 18, September,

19. Mitchell, M., Henderson, A., Groves, M., Dalton, M., \&Nulty, D., (2009): The objective structured clinical examination (OSCE): Optimizing its value in the undergraduate nursing curriculum. Nurse Education Today; 29(4): 398-404.

20. Mondal R., Sarkar S., Nandi M., Hazra A., (2012): Comparative Analysis Between Objective Structured Clinical Examination (OSCE) and Conventional Examination (CE) As a Formative Evaluation Tool in Pediatrics in Semester Examination for Final MBBS Students, Medical Education : Original Article,VOL.10 | NO. 1 | ISSUE 37 | JAN - MAR

21. Nicholas, J., Zyromski, E., (2003): Stare and Hollis W. Merrik. Surgery residents' perception of the objective structured clinical examination (OSCE). Current Surgery.; 60(5):533-537.

22. Nolti, D., Mitchell, M., Leffrey, C., \&Henderson, A., Groves M., (2011): Best Practice Guidelines for use of OSCEs: Maximising value for student learning. Nurse Education Today; . 31:145-151.

23. Noohi, E., Motesadi, M., Haghdoost, A., (2008): Clinical Teachersl' Viewpoints towards Objective Structured Clinical Examination.
Iranian Journal of Medical Education; vol: 8; No: 1; 15-20[In Persian]

24. Rushforth, H., (2007): Objective Structured Clinical Examination: Review Of Literature And Implication For Nursing Education. Nurse education today; 27:481-490

25. Selim, A., Ramadan, F., El-Gueneidy, M., Gaafer, M., (2012): Using Objective Structured Clinical Examination (OSCE) in undergraduate psychiatric nursing education: Is it reliable and valid? Nurse Education Today 32 283-288

26. Eldarir, A., \& Abd- el Hamid, A., (2013): Objective Structured Clinical Evaluation (OSCE) versus Traditional Clinical Students Achievement at Maternity Nursing: A Comparative Approach, IOSR Journal of Dental and Medical Sciences (IOSR-JDMS) e-ISSN: 2279-0853, p-ISSN: 2279-0861. Volume 4, Issue 3 (Jan.- Feb.), PP 63-68,www.iosrjournals.org

27. Smith,V., Muldoon, K., Biesty, L., (2012): The Objective Structured Clinical Examination (OSCE) as a strategy for assessing clinical competence in midwifery education in Ireland: A critical review. Nurse Education in Practice 12(5): 242-247

28. Smeltezer, C., Suzanne \& Bare, G., (2012): textbook of medical-surgical nursing .11th ed., Lippincott Williams \&Wilkins, .,

29. Stewart B., \& Laura K., Pharm. S., (2011): Objective Structured Clinical Examinations (OSCEs) Compared with Traditional Assessment Methods, American Journal of Pharmaceutical Education 2011; 75 (6).

30. Walsh M., bailey hill P., koren I., (2009): Objective Structure Evaluation of Clinical Competence: An Integrative Review. Journal of advanced nursing; 65(8):1584-1595

31. WHO (2003): Effective Teaching : A Guide for Educating Healthcare Providers. USAID. 